\title{
Donacuige, la literatura como excusa
}

\author{
Iñaki TOFIÑO QUESADA \\ Departament de Llengües Estrangeres \\ Institut Bosc de Montjuïc (Barcelona) \\ itofino@xtec.cat
}

\begin{abstract}
RESUMEN
El artículo pretende dar a conocer Las aventuras de un piloto en el golfo de Guinea, una narración considerada de forma unánime por la escasa crítica que la ha citado hasta ahora como la primera novela colonial sobre las posesiones españolas en el golfo de Guinea. Se expone un resumen de la obra así como las circunstancias históricas que la rodean (historia de la isla de Annobón y de la colonización española de la misma) y una hipótesis sobre el autor, que publicó bajo el seudónimo de Donacuige.
\end{abstract}

Palabras clave: Novela colonial española, Guinea Ecuatorial, Guinea española, Annobón, Hispanotropicalismo

[Recibido, julio 2012; aprobado, enero 2013]

Donacuige, literature as a pretext

\begin{abstract}
The article tries to present Las aventuras de un piloto en el golfo de Guinea, a story considered unanimously by the little scholars who have cited it so far to be the first colonial novel about the Spanish possessions in the Gulf of Guinea. We present a summary of the work and the historical circumstances surrounding it (history of the island of Annobon and its Spanish colonization) and a hypothesis about the author, who published under the pseudonym Donacuige.
\end{abstract}

Keywords: Spanish colonial novel, Equatorial Guinea, Spanish Guinea, Annobon, Hispanictropicalism 


\section{Introducción}

El domingo 14 de febrero de 1886 el periódico La Iberia, un diario liberal e iberista, publicaba una breve reseña bibliográfica en la que saludaba la aparición de un libro titulado Aventuras de un piloto en el golfo de Guinea, obra del doctor Antonio Quesada que publica bajo el pseudónimo de Donacuige (Donaquige según La Iberia), en el que el autor "estudia de modo especial y concreto la isla de Annobón, prometiendo hacer lo mismo en breve con Fernando Poo" (La Iberia 1886: 3). Se trata de la primera (y prácticamente única) referencia a un autor y a una obra que la escasa crítica que desde ese momento se ha dedicado a la literatura colonial española ha calificado de forma unánime como la primera ficción literaria sobre las colonias españolas del golfo de Guinea. Pero, ¿quién era ese autor y qué narraba en su novela?

Puesto que las historias y antologías de literatura guineana se ciñen a las obras escritas por guineanos después de la independencia, con alguna referencia excepcional a los trabajos de autores como Leoncio Evita o Daniel Jones, guineanos que publicaron antes de la independencia de la colonia, hay que limitarse a consultar la limitada bibliografía existente sobre literatura colonial, que no supera la decena de obras. La fuente de la que van a beber otras autores son los artículos del bibliógrafo Carlos González Echegaray, publicados sucesivamente en los Archivos del Instituto de Estudios Africanos del CSIC, en la revista misional La Guinea española y en la revista África 2000. Se trata básicamente de la misma información, corregida y aumentada según pasan los años. González califica la obra de "novela-pretexto", puesto que "aún siendo de imaginación y con argumento, es sólo una excusa para encajar al lector una lección de geografía, de historia, de política colonial o... de anticolonialismo". Según su parecer, "el pedantesco estilo de la obra no concierta con el tono de aventura que en la primera parte de ella quiso darle el autor" (González 1964: 77-78).

El artículo de 1965, publicado en cuatro entregas de mayo a agosto de la revista $L a$ Guinea española, es básicamente una reedición del anterior, dirigida esta vez no a los eruditos del CSIC sino a los lectores coloniales de la revista misional, publicada por los padres claretianos en Fernando Poo, y no modifica una coma de lo dicho en el anterior. De hecho, indica que se trata de la transcripción de una conferencia pronunciada en Madrid en el salón de actos del CSIC. Las opiniones se repiten en el artículo de 1989, aunque en esta ocasión las obras se clasifican por orden cronológico y no por géneros, de forma que la novela de Donacuige es la primera de la "etapa monárquica", de la que indica que "más que una novela es una serie de consideraciones sobre los problemas de la emigración, la colonización y la deportación, entreveradas con las andanzas de un novato piloto que se estrena viajando a Guinea" (González 1989: 41).

Carrasco González indica que se trata de "una primera referencia a los territorios españoles del golfo de Guinea en el siglo XIX" y concuerda con González al indicar que "no es una gran novela, en puridad tal vez no sea ni una novela". Sin embargo, apunta un hecho interesante: "Se sitúa el autor en esa corriente colonialista que empieza a formar partido en España. Busca aumentar la influencia de los africanistas y con esa pretensión escribe" (Carrasco 2000: 224).

Sin embargo, las escasas referencias a las posesiones tropicales africanas de España (tan sólo se habla de la remota isla de Annobón) y el hecho de no ver la luz la prometida segunda parte sobre la isla de Fernando Poo convirtieron esa pretensión en un mero proyecto. De la escasez de su importancia da fe el hecho de que Trujillo la despache con una única frase: "la primera novela $[\ldots]$ apenas ofrece algunas referencias a Fernando Poo" (Trujillo 2004: 6). 
Finalmente, la última referencia de que tengo constancia es la que aparece en la bibliografía anotada publicada por la colonial Erika Reuss, que, frustrada por el alto precio pagado por el ejemplar que posee para descubrir después que la historia no está completa, escribe: Es un libro curioso por su fecha de publicación (según mis investigaciones, es la primera novela publicada sobre Guinea) y proporciona algunos datos históricos; a pesar de ello, no resulta especialmente interesante. (Reuss 2008: 135)

Y hasta aquí toda la bibliografía sobre la obra. Sobre el autor, nada, el silencio más absoluto. Ni en el catálogo de la Biblioteca Nacional (que dispone de dos ejemplares), ni en su hemeroteca digital, ni en hemerotecas, bibliotecas o buscadores virtuales hay más referencias a Donacuige y a su narración. De ahí el interés por chapear el terreno, desbrozar, abrir camino y dar a conocer esta narración que inicia la andadura de la novela colonial española.

\section{La obra}

Resulta un tanto difícil calificar este libro, publicado en 1886 en Madrid por el establecimiento tipográfico de M. Minuesa. Según Pura Fernández, Manuel Minuesa de Lacasa fue un "infatigable impresor que desarrolló su actividad durante la segunda mitad del siglo XIX, la amplió con labores editoriales - con las que contribuyó a difundir la novela por entregas y la literatura de cordel- y llegó a formar parte del gobierno municipal de Madrid en 1872" (Fernández 1992: 226). Nos encontramos, pues, ante un impresoreditor que cuenta con las plumas de escritores populares y cuyo catálogo gozaba de gran aceptación entre el público; sin embargo, no parece que tuviera demasiado éxito al incluir a Quesada en su lista de autores.

Se trata de una narración en que un personaje anónimo describe, a instancias de sus compañeros de tertulia y para demostrar las bondades y posibilidades de la colonización española de la isla de Annobón, sus peripecias como piloto naval y su estancia en ese territorio. La historia tiene, ciertamente, escaso interés literario: la narración es completamente lineal, los personajes prácticamente arquetípicos (excepción hecha, quizá, del tío Belando, de quien nos ocuparemos más tarde), está plagada de largos pasajes que parecen copiados de algún tratado o enciclopedia que describiera los temas que se tratan (la geografía de la isla, el concepto de colonización, ideas sobre la deportación como instrumento del derecho penal...) y el narrador es casi un voyeur, un mirón, una excusa para hacer avanzar la narración.

Como muchas de las obras que se van a ocupar después de la Guinea española, ésta es una historia narrada en primera persona. En una reunión de amigos en un local de las Ramblas de Barcelona se discute sobre las posibilidades de colonizar las islas del golfo de Guinea. El narrador se mantiene en silencio, pero finalmente le piden que de su opinión al respecto, puesto que él conoce bien el tema que se trata:

Usted que ha estado en estos países de que hablamos y tienen motivos para conocerlos, ha tenido la paciencia de oír lo que de ellos decíamos sin protestar de lo erróneo de nuestro modo de ver, y sin ilustrarnos como es nuestro deseo, y aún me atrevo a decir su obligación. [...] Vive Dios que es gracioso que en España nadie sepa una jota de nuestras colonias y que todos hablemos de ellas. (Donacuige 1886: 9-10)

Ante esta demanda, el narrador redacta unas notas y se decide a publicar sus aventuras, que pretende dividir en dos partes. La primera (la única que llegó a ver la luz por lo que parece), cuenta la historia de su familia, una saga de industriales catalanes venidos a menos. Tras la muerte del padre y la madre, el narrador apoyado por una familia 
de benefactores, decide estudiar para marino y finalmente consigue hacerse a la mar, procurando, eso sí, esconder siempre cualquier dato que pudiera revelar su identidad: "En el día.... de .... de 188... embarqué en la fragata de vela Z., de la matrícula de Barcelona, mandada por D. P. R.” (Donacuige 1886: 57).

Tras un bautismo de mar que le lleva a Cádiz, Cuba y Puerto Rico regresa a Barcelona. Después se embarca con rumbo a las Filipinas y vuelve también a la Ciudad Condal. Allí se promete con la hija de su benefactor, pero lejos de aceptar algún puesto seguro en tierra vuelve a embarcarse en una expedición que debe llevar ciertas mercancías a una factoría catalana en Accra y acercarse a las islas del golfo de Guinea. Después de visitar Tenerife, Sierra Leona y Accra, su barco es interceptado por un navío de la marina inglesa que les obliga a poner rumbo a Sierra Leona. Allí se les acusa de traficar con esclavos, incidente que da lugar a una larga perorata de ardor patrio y de crítica feroz a los hijos de la pérfida Albión: "Funcionaban nuestras más famosas universidades en nuestra inmemorable Córdoba cuando usaban los ingleses el traje de esta gente [iban semidesnudos como los habitantes del África negra, se supone]" (Donacuige 1886: 113)

Tras algunas páginas destinadas a discurrir sobre la trata negrera y sobre su carácter nefando, el narrador llega a la conclusión de que la falsa acusación no es más que una excusa británica para entorpecer el comercio español en aquellas aguas. Aún así, no se produce su liberación sino que es abandonado en una isla que él cree desierta. Por única compañía, un krumán que le había acompañado en su cautiverio y que había saltado al bote en que le habían abandonado los ingleses. Después de preguntarle, el krumán responde que se encuentran en Annobón, algo que parece razonable al narrador y que inicia una parrafada sobre la situación geográfica de la isla, la cuarta de las situadas en el golfo de Guinea junto a Fernando Poo, Príncipe y Santo Tomás.

Aparecen después unos habitantes de la isla, que hablan una mezcla de portugués (el criollo portugués fá d'ambô, derivado del forro de Santo Tomé, de donde procedía la población de la isla) y castellano, por haber sido educados por los padres jesuitas, y que van describiendo con aburrida exactitud los accidentes del territorio, como si de un informe topográfico se tratara. Finalmente el narrador encuentra a quien será su compañero de fatigas: el tío Belando, un andaluz deportado a la isla que la hará de guía, le mostrará a sus habitantes y le acompañará en el viaje durante el cual, supuestamente, abandonarán la isla. A ese encuentro le siguen cinco páginas de discusión sobre la deportación como instrumento de corrección penal y otras diez de descripción geográfica de la isla y de sus posibilidades agrícolas (claramente destinadas a excitar el deseo de colonizar, ya que en el fondo no es otro el propósito de la obra).

Durante las caminatas por la isla, el narrador descubre los restos de una pequeña capilla y un personaje que celebra una especie de Eucaristía que le habla de la presencia de los padres capuchinos en la isla (según los documentos claretianos editados por Wulf estos frailes portugueses fueron los primeros en evangelizar la isla, aunque Caldeira habla de capuchinos bretones e italianos) y de la visita de un padre Sanmartín, "que nos dio mucha caña y se llevó a estudiar dos niños que no han vuelto" (Donacuige 1886: $180)$. Un elemento más para añadir verosimilitud a la narración, que pretende ser prácticamente un tratado sobre la isla; efectivamente, en los documentos claretianos se habla del padre Lorenzo Sanmartín y de dos niños procedentes de la isla que, educados por los religiosos, ayudaron al padre Sanmartín en una visita que hizo a Annobón, "a fin de que viéndolos tan bien vestidos y cultivados física y moralmente, estimasen a los españoles que tales bienes les proporcionan y entrasen además en el deseo de procurar iguales bienes a sus hijos" (citado en Wulf 1998: 41). 
Los habitantes de la isla, sin embargo, no parecen haberse sentido transportados por ningún fervor patriótico, puesto que después de la celebración de una pseudoeucaristía el narrador describe estupefacto un baile, una de las escenas más curiosas de la obra. Como será norma después en las novelas coloniales sobre Guinea, la descripción de la fiesta de los habitantes de la isla es una muestra de los miedos más profundos del narrador, que contempla asombrado como una "turba de negros y negras" (Donacuige 1886: 185) se pone a beber y a bailar. En esta ocasión no hay indicación de la desnudez de los bailarines, pero sí algo que pone los pelos de punta al europeo que contempla y narra la escena: su compatriota, que por lo que parece lleva años viviendo en la isla, no hace otra cosa que "levantarse en medio de aquellos danzantes guerreros y empezar a dar saltos y brincos y corvetas con tal agilidad y soltura que no podía sospecharse" (Donacuige 1886: 186). Un ejemplo de lo que en la terminología de los estudios postcoloniales anglosajones ha venido en llamarse "going native", la adopción de los usos y costumbres de los pueblos colonizados (o visitados por el antropólogo) que se consideraban inferiores, faltos de civilización y, por tanto, prácticamente propios de los animales. En un contexto de jerarquización de culturas, lo propio del europeo era mantener las apariencias y pasar por alguien superior culturalmente (aunque en la mayoría de ocasiones no fuera el caso), de forma que ver a un compatriota en una situación propia de africanos era, cuanto menos, curioso, sino reprobable y desagradable. El narrador de esta historia muestra una actitud ambivalente al respecto, pero no deja de dar su opinión sobre el baile del tío Belando entre los habitantes de Annobón: "Aquello fue el non plus de la admiración y del despecho mío al ver la degradación de mi compañero" (Donacuige 1886: 185).

Nos acercamos al final de la primera parte, que incluye digresiones sobre la emigración, la historia de la isla y los motivos para la colonización. Resulta curioso comprobar que una de las características del discurso que Gustau Nerín ha bautizado como "hispanotropicalismo" ya aparece en un momento tan temprano de la colonización: la vocación africana de los españoles, fruto de una historia que incorpora la Europa occidental y el Islam oriental. Así las cosas, el narrador explica que "unos pueblos como el nuestro [...] que lleva en sus venas la sangre del Norte y la ardiente de los árabes, es un pueblo apto para la primera base de una colonia, porque resiste y vence en la lucha, y asimila en la paz hasta amalgamar las razas inferiores" (Donacuige 1886: 214).

Finalmente, tras descubrir que el krumán que le había acompañado en su aventura ha tallado un bote con el tronco de un árbol, deciden salir a la mar a dar un paseo en barco. El tiempo se tuerce, el mar se encrespa y acaba la primera parte con una invocación a la Providencia, pues ya se ve el narrador ahogado en esas aguas. Puesto que ni la Biblioteca Nacional dispone de otros ejemplares ni los autores que la citan demuestran tener conocimiento de ella, cabe suponer que nunca se llegó a publicar la segunda parte de la narración. En cualquier caso, resulta evidente que el protagonista de la historia regresó a Barcelona, pues de otra manera no hubiera podido contar sus aventuras a sus amigos tertulianos.

\section{Historia de la isla}

Cuando en 1886 se publica la obra, hacía poco más de un siglo que España había firmado el tratado de El Pardo con Portugal, mediante el cual la corona portuguesa cedía el dominio de las islas de Fernando Poo y Annobón a cambio de algunos territorios en el continente americano. Según narra Caldeira en su artículo sobre la vida religiosa de la isla (Caldeira 2005), se trataba de una isla despoblada cuando los portugueses llegaron a 
ella por primera vez alrededor de 1470 y su población ha sido siempre escasa (unos cinco mil habitantes en 2004 según los datos del Instituto Español de Comercio Exterior). Durante el dominio portugués se pobló con esclavos africanos llevados desde Santo Tomé y la presencia de europeos fue mínima, en ocasiones limitada a un único portugués (Caldeira 2005: 2).

Los contactos con el exterior se limitaban a los barcos de paso y la presencia religiosa fue siempre irregular e inestable: capuchinos bretones e italianos y algunos canónigos de la catedral de Santo Tomé que llegaron en 1770 y fueron objeto de miles de provocaciones, incluida la práctica de relaciones sexuales delante de ellos para obligarlos a abandonar la isla (Caldeira 2005: 4). Sin embargo, los africanos de la isla aceptaban una mínima presencia blanca como "garantia de segurança contra eventuais raids para a captura de escravos e, sobretudo, contra a dominação, em condições mais desfavoráveis, por parte de outras potencias coloniais" (Caldeira 2009: 3). En estas condiciones de práctica independencia de facto de la isla, se negocian los tratados de San Ildefonso (1777) y de El Pardo (1778), unas negociaciones que Caldeira resume de forma muy gráfica: "Para a Espanha era literalmente, "meter uma lança em África", para Portugal era dar o que não tinha" (Caldeira 2005: 5).

A partir de entonces, se suceden en España gobiernos y acontecimientos políticos y sociales que exigen la necesidad de resolver la cuestión de la presencia española en las islas del golfo de Guinea. Sin embargo, la isla se mantendrá libre de cualquier control político europeo entre 1770 y 1885 , año en que llegará a la isla la primera misión de claretianos (Caldeira 2009: 5). Según la memoria de Moros y De los Ríos, el gobierno español había propuesto al gobierno inglés en diversas ocasiones $(1826,1839$ y 1841) la enajenación de las islas, aunque al final la venta nunca se llevó a cabo. En cualquier caso, parece cierto que había una corriente de opinión en el país que consideraba que lo mejor que se podía hacer era vender las islas y olvidarse de esas tierras que no generaban más que gastos al erario público. El periódico La Constitución en sus números 199 y siguientes se explicaba de este modo:

Con la cesión que Portugal nos hizo de estas islas, ninguna ventaja consiguió España; y sí entrar en crecidos gastos que solo aprovecharon á los habitantes de las del Príncipe y San Tomé. Aun hay más, declararon los expedicionarios, que , «habíamos sido engañados por los portugueses y que si bien podrían resultar ventajas para la compra de esclavos, cera, marfil y palo de tinte que venden los negros de la costa inmediata, no era posible disimular que para establecerse ocurrían grandes dificultades y que, consideradas las circunstancias en que se encontraban las cosas, saldría el rey muy perjudicado, añadiendo que los portugueses siempre lo habían creído así también, cuando nunca se habían establecido en aquella, ni hecho el comercio con sus habitadores.»

Con relación de Annobón dicen los mismos expedicionarios «que el número de habitantes era muy reducido, el terreno tan montuoso que de las 16 millas cuadradas que tiene, apenas hay tres que puedan cultivarse, y que por esta razón habían abandonado los negros el plantío de las cañas de azúcar que emprendió en 1656 un tal Diego Delgado, vecino de San Tomé, considerando por lo tanto que de ningún modo convenía a la monarquía española el establecimiento en Annobón.»

En nuestro juicio no solo las islas de Fernando Póo y Annobón están bien vendidas, sino que lo estuvieran igualmente las Marianas en Asia. Estas islas mandadas por un sargento inválido, creemos distan, si la memoria no nos es infiel, quinientas leguas de las Filipinas de que dependen. Pues nuestros lectores se admirarán cuando sepan que el gobernador de las Marianas recibe las comunicaciones del capitán general de Filipinas por 
Londres, es decir, que para quinientas leguas se necesitan catorce o dieciséis meses. Nada más prueba la importancia de las Marianas. (Moros 1844: 63-64)

Hubo intentos de atraer capital privado a la empresa colonizadora, cuyo presupuesto público se había reducido a la mitad después de la revolución de 1868, pero "la respuesta del capital español fue casi inexistente, y sólo mostraron interés por la Colonia especuladores que pretendían beneficiarse de las ayudas del Estado, o ilusos que soñaban encontrar un nuevo Eldorado." (Castro 2003: 195). Se llegó a organizar una expedición de colonos, que fracasó, y en 1869 se reúne una Junta Consultiva para "averiguar si aquel país reúne condiciones bastante favorables para crear una provincia española, ventajosa al Estado, con los oportunos y convenientes medios, y cuáles deben ser éstos; o si convendrá más perder lo gastado y abandonar este proyecto" (Gaceta de Madrid número 352, 18 de diciembre de 1869). Según Castro, aunque las resoluciones eran en general favorables al abandono de las posesiones, el interés político prevaleció y las posesiones se mantuvieron bajo soberanía española (Castro 2003: 203).

Cabe decir, que no solo se trataba de intereses políticos seculares. En un texto que demuestra la constante interrelación entre las autoridades civiles y las religiosas que va a caracterizar la colonización de los territorios del golfo de Guinea a lo largo de los siglos diecinueve y veinte, un anónimo fraile claretiano denuncia a los que hablan de la aridez de la isla de Annobón y pretenden el abandono de la isla:

Quien tales falsedades escribía, creyó sin duda o que nunca se había de esclarecer la verdad con posteriores visitas y estudios concienzudos del terreno de la isla, o que se había de creer tan crédulamente que bastase su aseveración no viniendo acompañada de observaciones hechas por el mismo escritor o a lo menos refiriéndose a otros (citado en Wulf 1998: 45).

Así las cosas, no sólo se trataba de una cuestión política, de orgullo patrio, sino también de una cuestión religiosa, de defensa de la labor misionera de la iglesia católica frente a la presencia de misioneros de otras confesiones. En este contexto, pues, es en el que se publica en Madrid la narración de Antonio Quesada.

\section{El autor y sus personajes: carácter pionero de la narración}

Como ya hemos indicado, La Iberia saluda al "doctor Antonio Quesada" como autor de la obra y en el ejemplar de la Biblioteca Nacional hay una firma manuscrita que indica Antonio Quesada García, por lo que parece claro que el pseudónimo es una sigla del nombre del autor (DON A Q y G = Donacuige). ¿Se trata del mismo Antonio Quesada García que en diciembre de 1869 obtuvo una plaza de alumno interno en la Facultad de Medicina de Madrid tras ser nombrado por el decano, Pere Mata, según noticias del diario La Esperanza? ¿Del Antonio Quesada que La Correspondencia de España informaba de que había sido nombrado segundo médico de la Armada en noviembre de 1872? ¿Era el Antonio Quesada que obtuvo en enero de 1880 el título de practicante de primera clase de medicina, según noticia de La Correspondencia de España? Imposible saberlo, el nombre y los apellidos son demasiado comunes y exigirían mayor investigación, pero las pistas permiten sospechar que efectivamente se trataba de un médico, alguien, pues, con la cultura y los medios suficientes para enfrentarse a la recopilación de datos y la elaboración de una obra así. 
En cualquier caso, más allá de las dudas que pueda suscitar la autoría del texto, nos encontramos ante un mensaje claro: la necesidad de colonizar las islas del golfo de Guinea. Pero hay más. La isla, prácticamente desconocida para los habitantes de la Península, está habitada no solo por esclavos libertos procedentes de Santo Tomé sino también por un curioso personaje, el tío Belando, que el narrador nos cuenta

que era sevillano y que había vivido en Sevilla ejerciendo el oficio de esquilador, hasta que después de la revolución del..., en la que no tuvo ni arte ni parte, y sin que nadie pensarlo pudiera, le habían cogido y conducido a Cádiz, donde en unión de otros tan inocentes o más que él, los habían embarcado para Fernando Poo (Donacuige 1886: 144).

Un andaluz deportado al golfo de Guinea, efectivamente. Una Real Orden de 20 de junio de 1861 había creado un presidio en Fernando Poo y otro en las Marianas, que el gobierno de O'Donnell parece que pretendía convertir en colonias penales. Muchos de los desterrados allí fueron independentistas cubanos (véanse Barcia 2003, González Echegaray 2003 y Márquez Acevedo 1998), pero los primeros en llegar fueron los detenidos y condenados por haber participado en la sublevación de Loja e Iznájar (Gabriel 2006: 211), la llamada Revolución del pan y el queso, que tuvo lugar el 28 de junio de 1861 cuando un numeroso grupo de jornaleros, encabezados por Rafael Pérez del Álamo y al grito de "¡Viva la República y muera la Reina!" asaltaron el cuartel de la Guardia Civil de Iznájar como consecuencia de las pésimas condiciones de trabajo, frustrados por no poder acceder a los beneficios de la desamortización. Según Gabriel, treinta y tres fueron deportados a Fernando Poo, pero después de la muerte de cuatro y ante la grave situación del resto, los que quedaban vivos fueron puestos en libertad y regresaron a la Península. No así el personaje de Donacuige, que cuenta que el maestro de víveres y el pañolero del barco que los transportaba le ayudaron a huir, dejándole en tierra con unas cuantas semillas para que pudieran subsistir.

Aquella deportación y sus resultados pasaron a llenar el imaginario peninsular y estigmatizaron la isla de Fernando Poo como un infierno maldito (Gabriel 2006: 211), como una maldición (García Cantús 2005: 479). Ésa era la imagen mental que tenía cualquier lector medianamente informado: unas regiones malsanas con las que el gobierno no sabía qué hacer, si convertirlas en colonia penal, si poblarlas y explotarlas o si abandonarlas definitivamente. De ahí que la nota de La Iberia de 1886 indicara sin ambages que:

En mala empresa se ha metido el autor. La colonización es este país [sic] perfectamente desconocida, y sus graves problemas olvidados por la opinión general, ocupada en cuestiones del momento y llena de afanes para vivir al día. Para la colonización precisa constancia [sic], y nada hay más inconstante que nuestro pueblo (La Iberia 1886: 3).

La colonización se llevó a cabo, sí, pero Quesada García quedó completamente olvidado, excepto para unos pocos autores que están de acuerdo en concederle a su obra el título de "primera novela publicada sobre los territorios españoles de Guinea", aunque cabría compararla con otras publicaciones de la época, como las narraciones de los viajes de Manuel Iradier, para establecer algunos criterios que permitieran catalogarla como "ficción", autobiográfica, pero ficción al fin y al cabo. A pesar de todo, es importante destacar que su autor incluye algunos tropos que después se convertirán en moneda corriente en otras obras literarias sobre la España tropical: 
- La importancia de la presencia catalana en la colonización. El autor se presenta como catalán y su viaje tiene como objetivo negociar con una factoría catalana en Accra, actual capital de Ghana, que fue puerto negrero desde el siglo XVII y capital de la Costa de Oro, colonizada por portugueses, daneses, suecos y británicos.

- La descripción de la vestimenta de los africanos y en especial de su fascinación por los sombreros europeos, que al autor le parecen viejos y andrajosos. Un tropo que servirá más adelante para demostrar la jerarquía cultural que pretenden establecer los autores españoles en su literatura colonial.

- La descripción de los bailes africanos, considerados como una muestra del carácter sensual y envilecido de los habitantes de los trópicos.

- El discurso hispanotropicalista, que pretende demostrar la innata vocación colonizadora de los españoles frente a otros tipos de colonización que se consideran perversos (comparados, evidentemente, con la supuesta bondad del colonialismo español).

No aparecen aquí elementos como la descripción de la costa africana (un tropo que se convertirá en clásico cada vez que se describa el viaje desde la Península a las posesiones españolas del golfo de Guinea) ni la imagen del hombre negro como parte del paisaje, de la selva. Sin embargo, siguiendo las premisas de Franco Moretti, se puede afirmar que comparte con otras novelas coloniales una percepción absolutamente linear del espacio:

Colonial romances have no bifurcations. [...] In these stories -as in their archetypal image: the expedition that moves slowly, in single file, towards the horizon- there is only a linear movement: forwards, or backwards. There are no deviations, no alternatives to the pre-scribed path, but only obstacles -and, therefore, antagonists. Friends, and foes. (Moretti 1999: 58)

Es fácil comprobar en este caso como el espacio determina una determinada categoría de narración. Los mapas actuales de la isla no servirían para situar los asentamientos y accidentes geográficos que se citan en la novela, pero un mapa más antiguo, como el del padre Pérez del Amo (1966: 10), revela con asombrosa transparencia el recorrido del narrador desde su llegada a la isla: la punta Norte o del Palmar, el asentamiento de San Antonio, el pico del Fuego, la isla de la Tortuga, el pico del Centro, las bahías de San Pedro y de Santa Cruz, el pico del Sur... La narración avanza siguiendo la geografía de la isla y en el fondo no tiene mayor interés que el meramente descriptivo. ¿Viajó alguna vez el señor Quesada García a la isla? Resulta imposible saberlo, pero, a fin de cuentas, poco importa. Con la probable ayuda de alguna memoria sobre expediciones anteriores creó un documento, un testimonio, una ficción literaria, que le sirvió para su principal objetivo: dar publicidad a la isla y promover la colonización española de la misma.

\section{Bibliografía}

BARCIA, María del Carmen (2003). "Desterrados de la patria. Cuba 1869-1898". Universidad de La Habana. 258: 31-56.

CALDEIRA, Arlindo Manuel (2005). "Medo e religião popular na ilha de Ano Bom. Uma aproximação histórica (séculos XVI-XIX)", in Congresso internacional $O$ 
espaço atlântico de Antigo Regime: poderes e sociedades, Faculdade de Ciências Sociais e Humanas da Universidade Nova de Lisboa, 2-5 novembro 2005.

(2009). "Organizar a liberdade. Independência de facto na ilha de Ano Bom durante os séculos XVIII e XIX" in Between Three Continents: Rethinking Equatorial Guinea on the Fortieth Anniversary of Its Independence from Spain. Hofstra University, Hempstead (New York). 2-4 2009.

CARRASCO GONZÁLEZ, Antonio (2000). La novela colonial hispanoafricana. Las colonias africanas de España a través de la historia de la novela. Madrid: Casa de África-Sial Ediciones.

CASTILLO, Santiago (coord.); OLIVER, Pedro (coord.) (2006). Las figuras del desorden. Heterodoxos, proscritos y marginados. Madrid: Siglo XXI.

CASTRO, Mariano L. de (2003). "La Revolución de 1868 y la Guinea Español." Cuadernos de Historia Contemporánea. 2003: 191-204.

CORRESPONDENCIA DE ESPAÑA, La (1872). "Han sido nombrados segundos médicos de la armada". 27 de noviembre: 2.

(1880). “Comisión de personal". 10 de enero: 2.

DONACUIGE (1886). Aventuras de un piloto en el golfo de Guinea. Madrid: Establecimiento tipográfico de M. Minuesa.

ESPERANZA, La (1869). "Hoy se ha reunido el claustro de la facultad de medicina". 18 de diciembre: 4.

FERNÁNDEZ, Pura (1992). "Datos en torno a la bibliografía y difusión de la literatura popular en el Madrid del siglo XIX: la imprenta de Manuel Minuesa (1816-1888)". Anales del Instituto de Estudios Madrileños. 31: 225-238.

GABRIEL, Pere (2006). "Más allá de los exilios políticos: Proscritos y deportados en el siglo XIX" in Castillo (coord.): 197-222.

GARCÍA CANTÚS, Dolores (2005). "Fernando Poo: Una aventura colonial española en el África Occidental (1778-1900)". Directora: Carmen García Monerris. Universitat de València, Departamento de Historia Contemporánea.

GONZÁLEZ ECHEGARAY, Carlos (1964). "El África Ecuatorial a través de la novela y la poesía actuales". Archivos del Instituto de Estudios Africanos. 70: 67-107.

(mayo - agosto 1965): "El África Ecuatorial a través de la novela y la poesía”. La Guinea Española. 1.591-1.594: 115-129, 148-157, 180-197, 222-227.

(1989): "La novela en lengua española sobre Guinea Ecuatorial. Etapas de una producción literaria". África 2000. 9: 40-45.

(2003). "Cubanos en Fernando Póo. Un capítulo de las memorias de John Holt”. Cuadernos de Historia Contemporánea. 2003: 205-212.

IBERIA, La (1886). "Bibliografía". 14 de febrero: 3.

MÁRQUEZ ACEVEDO, Javier (1998). "Convictos cubanos deportados a Canarias y África durante la represión del independentismo, 1868-1900". Boletín Millares Carlo. 17: 103-119.

MINISTERIO DE LA GUERRA Y DE ULTRAMAR (1861). "Reales órdenes". Gaceta de Madrid. 9 de julio: 1.

MINISTERIO DE ULTRAMAR (1869). "Decreto." Gaceta de Madrid. 18 de diciembre: 1 .

MORETTI, Franco (1999). Atlas of the European Novel (1800-1900). Londres: Verso.

MOROS, José de y Juan Miguel de los Ríos (1844). Memorias sobre las islas africanas de España: Fernando Poo y Annobón. Madrid: Compañía Tipográfica. 
NERÍN, Gustau (1997). "Mito franquista y realidad de la colonización de la Guinea española". Estudios de Asia y África. 32.1: 9-30.

(2008). "La Guinea espanyola, una colònia catalana?". El País. 25 de septiembre.

PÉREZ DEL AMO, Manuel María, CMF (1966). Compendio de geografía e historia de la Guinea Ecuatorial. Fernando Poo: Imprenta de los Misioneros.

REUSS, Erika (2008). Guinea Española - Guinea Ecuatorial. Estudio de una biblioteca guineana. Madrid: Libris (Asociación de Libreros de Viejo).

TRUJILLO, José Ramón (2004). "Fuentes documentales del español en el África subsahariana. Tradición, traducción y modernidad”. Linguax. Revista de Lenguas Aplicadas. 1: 1-33.

WULF, Valerie de (1998). Documentos sobre Annobón. Vic: Ceiba (Documentos de la colonización 5). 